\section{Gerbil runway performance under hunger motivation}

\author{
JAMES H. REYNIERSE, MICHAEL J. \\ SCAVIO, JR., 1 and JAMES D. ULNESS, 2 \\ University of Nebraska at Lincoln, Nebr. \\ 68506
}

Three experiments report the effects of food deprivation and drive shifts upon acquisition and extinction of gerbil nunway performance.

The present three experiments investigated the effects of motivational variables upon gerbil runway performance. Although intended to be preliminary for another problem, the increasing popularity of gerbils as Ss for behavioral investigation suggested that our results may be more generally useful, providing relevant information for further investigations of gerbil behavior.

\section{EXPERIMENT 1}

Experiment 1 examined the influence of food deprivation upon gerbil runway performance.

\section{Method}

Twenty-seven adult male Mongolian gerbils were initially food deprived for $22 \mathrm{~h}$ and given up to 21 runway familiarization trials with a two-45-mg-Noyes-pellet reward. The runway ( $6 \mathrm{ft} \times 4$ in. $\times 9$ in.) had a goal box and start box, each $1 \mathrm{ft}$ long, attached to either end of the alley. The start box was separated from the runway proper by a guillotine door; a 2 -in.-wide partition separated the goal box from the runway and blocked the incentive from view until $S$ entered the goal box. The stem of the runway was painted flat grey, the start box flat white, and the goal box flat black. Hinged lids of translucent clear plastic covered the entire alley. Microswitches attached to the start-box door and goal-box floor were connected with a Standard Electric Timer to measure running time.

Following pretraining, Ss were placed on their experimental deprivation schedule, 22 , 12 , or $6 \mathrm{~h}$ food-deprived, and given five massed runway trials daily for 14 consecutive days. On each trial the start box door was raised and when $S$ entered the runway, was closed behind it. The trial was terminated when $S$ entered the goal box or after 180 sechad elapsed. When $S$ consumed the two-45-mg-Noyes-pellet reward, $S$ was returned to the start box and the next trial was begun. After completing the fifth trial S was retumed to its home cage where Lab Blox were available ad lib. This food was later removed from the cages before the next session in correspondence with each group's deprivation schedule. During the last 4 training days each S's daily food and water intake were recorded.

Results and Discussion

Mean median running time in seconds for the first 2 pretraining days and all 14 training days are summarized in Fig. 1. Initial pretraining running times were highly variable and differences appearing in Fig. 1 were nonsignificant. For the 14 training days, a log transformation was performed on each S's daily median running time and the means of these analyzed by analysis of variance. The mean effect for deprivation was significant $(F=6.92, \quad d f=2 / 24$, $\mathrm{p}<.05$ ) reflecting the superiority of the 22-h group which ran significantly faster than either the 12- or 6-h conditions which did not differ from each other. The effect for days was significant as a main effect $(F=58.43, \mathrm{df}=13 / 312, \mathrm{p}<.001)$ and in interaction with deprivation conditions $(F=9.68, \mathrm{df}=26 / 312, \mathrm{p}<.001)$, reflecting primarily further acquisition of the running response for the $22 \mathrm{~h}$ group as these Ss ran faster with continued training, and an increase in running time for $12-\mathrm{h}$ Ss. This initial faster running speed is the only difference distinguishing the 12- and 6-h conditions.

Table 1 summarizes the mean food and water intake for $S s$ in each deprivation condition during the last 4 training days. Paralleling the runway behavior, $S$ s in the 22-h condition ate less than $\mathrm{Ss}$ in either the 12- or 6 - $\mathrm{h}$ deprivation conditions $(F=4.503, d f=2 / 24, p<.05)$ but drank more $(F=6.68, \mathrm{df}=2 / 24, \mathrm{p}<.01)$. Finally, for both food and water intake, the 22-h-food-deprived group differed significantly from both the 12 - and 6 -h groups which did not differ from each other.

\section{EXPERIMENT 2}

This study extends Experiment 1 by first shifting drive conditions and then extinguishing $\mathrm{Ss}$ under the original fooddeprivation conditions.

\section{Method}

The Ss, apparatus, and procedures were those of Experiment 1 except that drive conditions were shifted and extinction procedures were introduced. Within each

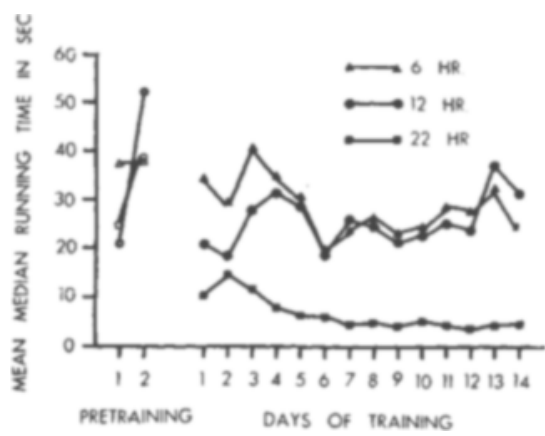

Fig. 1. Mean running time in gerbils, 22, 12 , or $6 \mathrm{~h}$ food-deprived.

original food-deprivation condition three Ss were unshifted, i.e., remained at the original drive condition, and three Ss were shifted to each of the other conditions. Following 8 days of drive shift, each $S$ was again switched to its original drive condition for another 8 days. Throughout, each $S$ continued to receive five massed runway trials daily with a reward of two 45-mg Noyes pellets. During the first drive shift, one $S$, shifted from 6 to $22 \mathrm{~h}$ of deprivation, died, and the mean of his postshift scores was used to main tain an equal number of observations in each cell without increasing degrees of freedom for that shift. During the 5 days of extinction experimental procedures remained unchanged except that the Noyes-pellet reward was omitted.

\section{Results and Discussion}

Mean median running time in seconds during both drive shifts are summarized in Fig. 2. Since there were two shifts, each drive shift was analyzed separately. A $\log$ transformation was performed on each S's daily median running time and the means of these analyzed by analysis of variance. For the initial drive shift, preshift drive condition was not significant either as a main effect or in interaction. The only significant effects were those for the postshift drive condition $(F=3.575$, $\mathrm{df}=2 / 18, \mathrm{p}<.05)$ and days $(\mathrm{F}=14.487$, $\mathrm{df}=7 / 126, \mathrm{p}<.001)$. For the second shift back to original drive conditions, preshift drive conditions were not significant. Again, both the postshift drive condition $(\mathrm{F}=6.809, \mathrm{df}=2 / 17, \mathrm{p}<.01)$ and days $(F=4.13, \mathrm{df}=7 / 119, \mathrm{p}<.001)$ were significant. These results reflect the consistent superiority of the $22-\mathrm{h}$ deprivation condition irrespective of experience with prior,

Table 1

Mean Water Intake and Food Intake for the Last Four Training Days

Food Deprivation Condition

\begin{tabular}{lllllll} 
& \multicolumn{2}{c}{22 hours } & \multicolumn{2}{c}{12 hours } & \multicolumn{2}{c}{6 hours } \\
Intake & $\mathrm{M}$ & $\mathrm{SD}$ & $\mathrm{M}$ & $\mathrm{SD}$ & $\mathrm{M}$ & $\mathrm{SD}$ \\
\hline Food (g) & 3.625 & 1.107 & 6.069 & 1.96 & 6.18 & 1.74 \\
Water (cc) & 9.416 & 3.3 & 5.777 & 2.403 & 5.763 & 2.43 \\
\hline
\end{tabular}




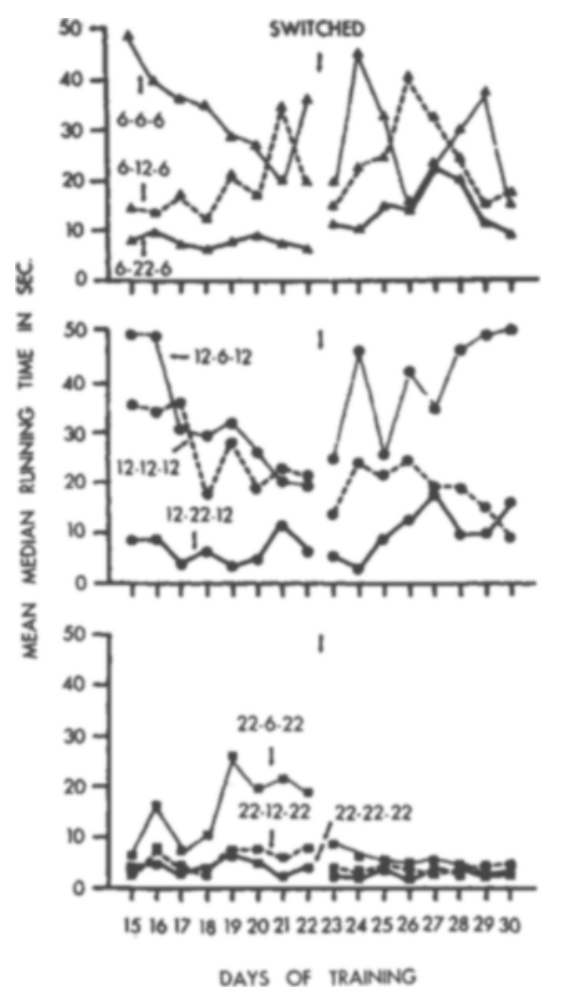

Fig. 2. Mean running time during two successive deprivation shifts.

preshift drive conditions and the fact that during both shifts some time was required to adjust to the abrupt shifts in drive condition. During the second shift, pre- and postshift drive conditions interacted with days $(\mathrm{F}=5.145, \mathrm{df}=28 / 119, \mathrm{p}<.001)$ and this effect is primarily due to the uniform and immediate rapid running in all Ss $22 \mathrm{~h}$ food-deprived. Analysis of variance performed on extinction scores showed that the effect for drive condition $(F=5.822$, $\mathrm{df}=2 / 23, \mathrm{p}<.01)$ and days $(\mathrm{F}=5.623$, $\mathrm{df}=4 / 92, \mathrm{p}<.001$ ) were significant, indicating a greater resistance to extinction in the Ss $22 \mathrm{~h}$ food-deprived and an overall but highly variable increase in running time with successive days of extinction.

The results of food deprivation in Experiment 1 and drive shift and extinction procedures in Experiment 2 are entirely consistent. In both, 6 - and 12 -h food

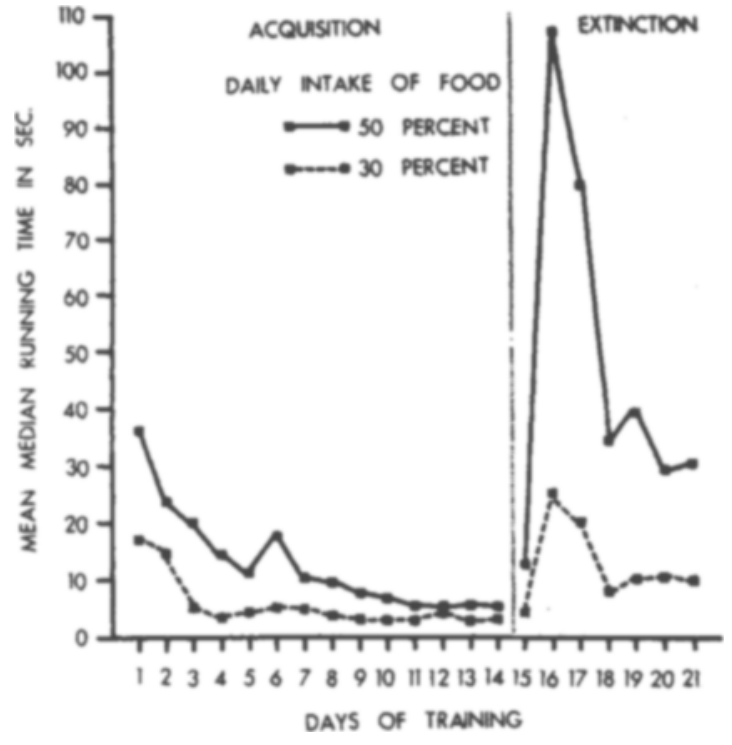

Fig. 3. Mean running time during acquisition and extinction in gerbils receiving either a $50 \%$ or $30 \%$ daily food ration.

deprivation produced highly variable results while only $22-\mathrm{h}$ food deprivation was a satisfactory procedure for motivating and controlling gerbil runway behavior.

\section{EXPERIMENT 3}

This study used a daily ration technique for examining the effects of food deprivation upon gerbil runway performance.

\section{Method}

Eleven Mongolian gerbils were given 12 days ad lib food and water during which time each S's food intake was recorded daily after the remaining food was weighed and subtracted from the ration given $24 \mathrm{~h}$ earlier. On all subsequent days each $S$ received a restricted daily food ration consisting of either $50 \%$ or $30 \%$ of its mean ad lib food intake. Six Ss were placed on a $50 \%$ and five Ss on a $30 \%$ restricted ration and received nunway training for 14 consecutive days. The runway and runway training were identical to that of Experiment 1 except that the familiarization and pretraining procedures were discontinued. Seven days of extinction also used identical runway procedures except that the two. Noyes-pellet reward was omitted. Results and Discussion

Mean median running time in seconds during acquisition and extinction procedures are summarized in Fig. 3. A $\log$ transformation was performed on each S's daily median running time and the means of these analyzed by analysis of variance. The effect for ration was significant during both acquisition and extinction $(F=11.095$, $\mathrm{df}=1 / 9, \mathrm{p}<.01$ and $\mathrm{F}=20.06$, $\mathrm{df}=1 / 9$, $\mathrm{p}<.005$, respectively), an effect which is due to the superior performance of the $30 \%$ condition throughout acquisition and extinction. The main effect for days was also significant during both acquisition and extinction $\quad(F=13.43, \quad d f=13 / 117$, $\mathrm{p}<.001$ and $\mathrm{F}=25.023, \mathrm{df}=6 / 54$, $p<.01$, respectively), reflecting the decreased running times for both groups with successive days of acquisition and increased running times for both groups with successive days of extinction. Considering the uniform and stable effects produced by the food ration technique, these results suggest that the food ration technique yields greater motivational control than the food deprivation technique of Experiments 1 and 2 , and is the preferred procedure.

\section{NOTES}

1. Now at State University of Iowa, Jowa City, lowa 50012.
2. Now at Concordia College. 